\title{
Wegener Granulomatosis: Otologic Manifestation as First Symptom
}

\author{
Carla Fabiane da Costa $^{1}$ Jose Fernando Polanski ${ }^{1}$ \\ ${ }^{1}$ Department of Otorhinolaryngology, Hospital Universitario \\ Evangelico de Curitiba, Curitiba, PR, Brazil \\ Int Arch Otorhinolaryngol 2015;19:266-268.
}

\begin{abstract}
Address for correspondence Carla Fabiane da Costa, Resident Doctor, Department of Otorhinolaryngology, Hospital Universitário Evangélico de Curitiba, Rua Pedro Viriato Parigot de Souza 3288, Curitiba, PR 81200100, Brazil (e-mail: carlafabi20@hotmail.com).
\end{abstract}

\section{Introduction}

Wegener granulomatosis (WG) is a rare multisystem autoimmune disease of unknown etiology. ${ }^{1,2}$ It is a systemic vasculitis, affecting small and medium-sized vessels of the upper and lower respiratory tract and kidneys, including necrotizing granulomatous inflammation. ${ }^{2,3}$ WG has a spectrum of clinical presentations that includes recurrent respiratory infection, renal manifestations, and nonspecific systemic symptoms. Otologic manifestations are occasionally the first to appear in 20 to $60 \%$ of cases of WG, and serous otitis media is the most common presentation in ear disease. ${ }^{4-6}$ However, WG is not a common diagnosis in ear, nose, and throat (ENT) practice. We describe a case of a 50-year-old woman with severe bilateral hearing loss as the first symptom of the disease.

\section{Differential Diagnosis}

The differential diagnosis of WG with otologic manifestations may include tuberculous otitis media, cholesteatoma, Langerhans cell histiocytosis, neoplastic diseases, and other forms of vasculitis, sarcoidosis, and systemic lupus erythematosus.

Tuberculous otitis media is characterized by painless otorrhea that fails to respond to the usual antimicrobial

received

May 9, 2014

accepted after revision

July 1, 2014

published online

November 11, 2014
DOI http://dx.doi.org/

10.1055/s-0034-1387164. ISSN 1809-9777. treatment in a patient with evidence of tubercle infection elsewhere, followed by multiple tympanic membrane perforations, abundant granulation tissue, bone necrosis, and preauricular lymphadenopathy. Deafness is out of proportion with the apparent degree of development of disease seen in the otoscopy.

An ear exam may show a pocket or perforation in the eardrum often with drainage when cholesteatoma occurs.

Sarcoidosis is an idiopathic disease that presents in anatomic areas of concern to otorhinolaryngologists. It can cause dysfunction of both auditory and vestibular systems. In patients known previously to have sarcoidosis, this disease should be seriously considered. In patients presenting with otologic disorders and associated facial nerve paralysis or other neuropathies, uveitis, granulomatous meningitis, or diabetes insipidus, sarcoidosis should be suspected. An examination of the eyes as well as a chest X-ray is imperative. Sudden and fluctuating neurosensory hearing loss has been reported.

\section{Case Report}

The patient presented with complaints of severe and progressive bilateral hearing loss with onset 6 months

Copyright $(2015$ by Thieme Publicações License terms Ltda, Rio de Janeiro, Brazil 


\section{Audiogram}
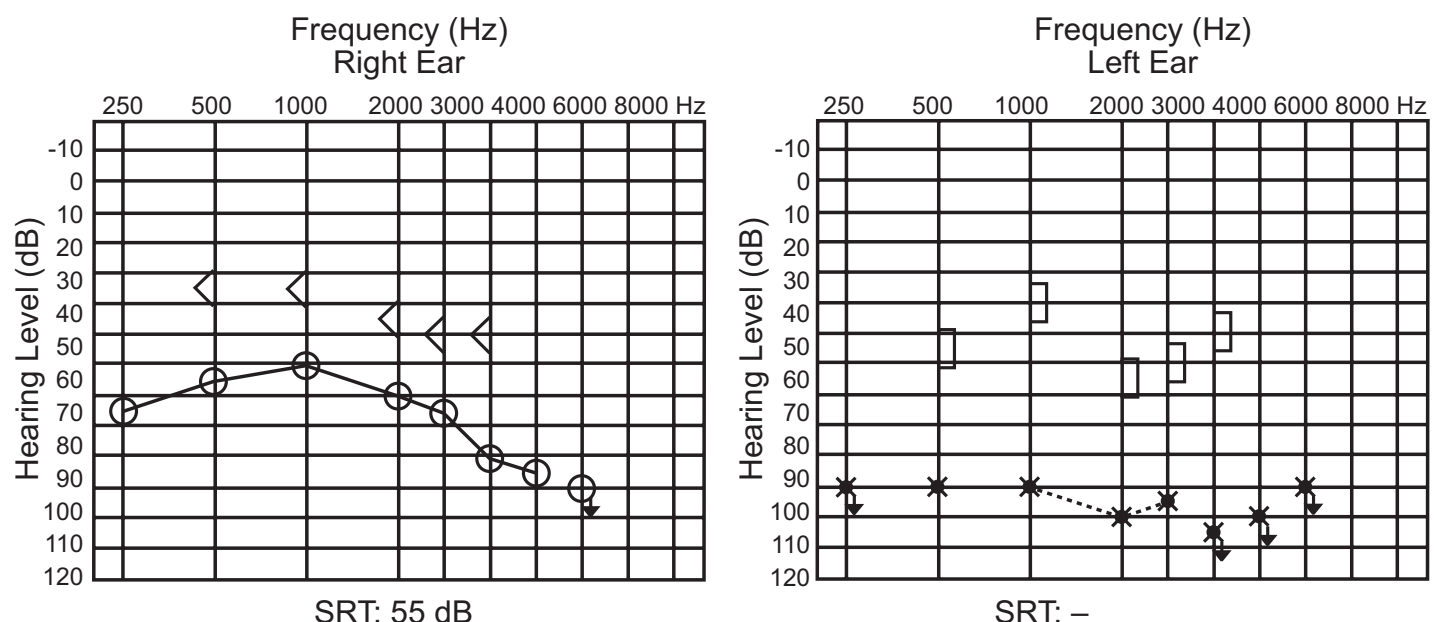

Fig. 1 Audiogram before treatment. Abbreviation: SRT, speech reception threshold.

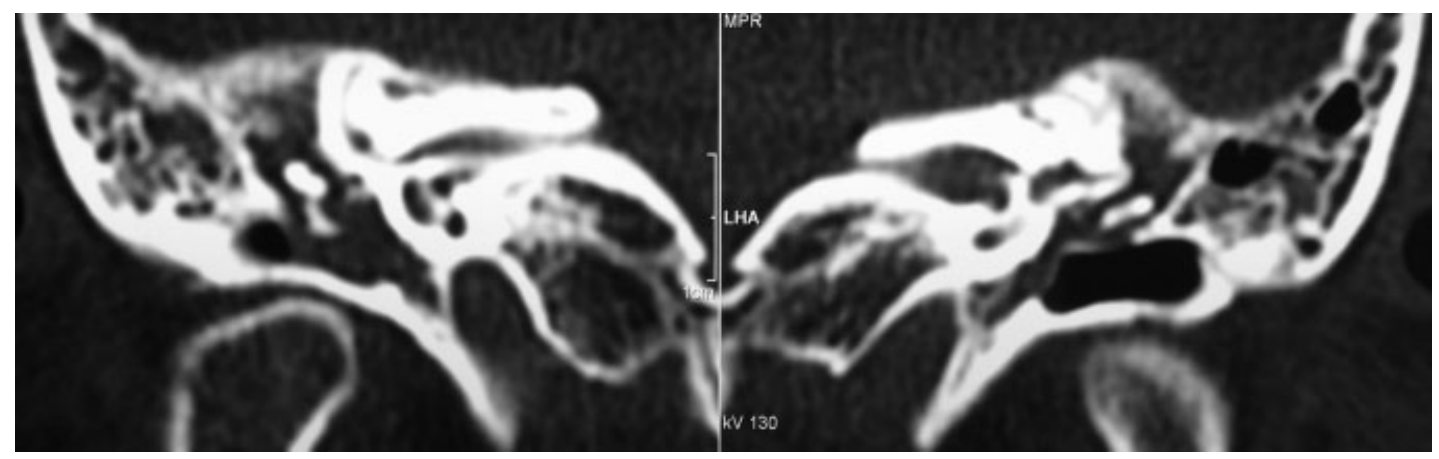

Fig. 2 Computed tomography of the temporal bone.

previously. Symptoms evolved with otorrhea and pain refractory to broad-spectrum antibiotics and nonsteroidal anti-inflammatory drugs. During ENT examination, otoscopy showed bilateral thickening and retraction of the tympanic membrane and fluid in the middle ear, with no other clinical findings. After carrying out the audiometry (-Fig. 1) and emittanciometry, ventilation tubes were placed bilaterally.

After 1 month, the patient complained of weight loss (7 kg/mo), lack of appetite, fevers, night sweats, asthenia, and dry cough. Laboratory findings revealed mild normochromic normocytic anemia, Westergren erythrocyte sedimentation elevated rate, elevated C-reactive protein, nonreactive Mantoux tuberculin skin test, negative sputum smear, and negative HIV antibody.

Computed tomography of the temporal bone (-Fig. 2) and audiometry were performed. Chest computed tomography showed the presence of pulmonary nodules and masses with excavation areas in the left upper and lower lobes, with moderate pericardial effusion (-Fig. 3). Bronchoscopy with transbronchial biopsy showed inconclusive pathologic result, with the presence of discrete fibrous thickening and septal fibrosis nodular focus.
The patient was also referred to the Department of Rheumatology for antineutrophil cytoplasmic antibodies testing, which was positive, and then antiproteinase 3 antibody testing, which was also positive, confirming the diagnosis.

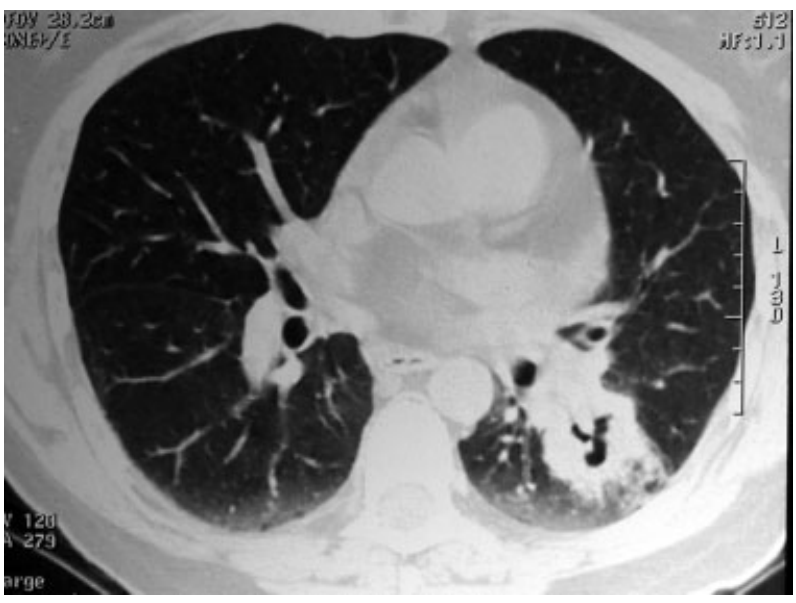

Fig. 3 Chest computed tomography showed the presence of pulmonary nodules and masses with excavation areas in the left upper and lower lobes and moderate pericardial effusion. 


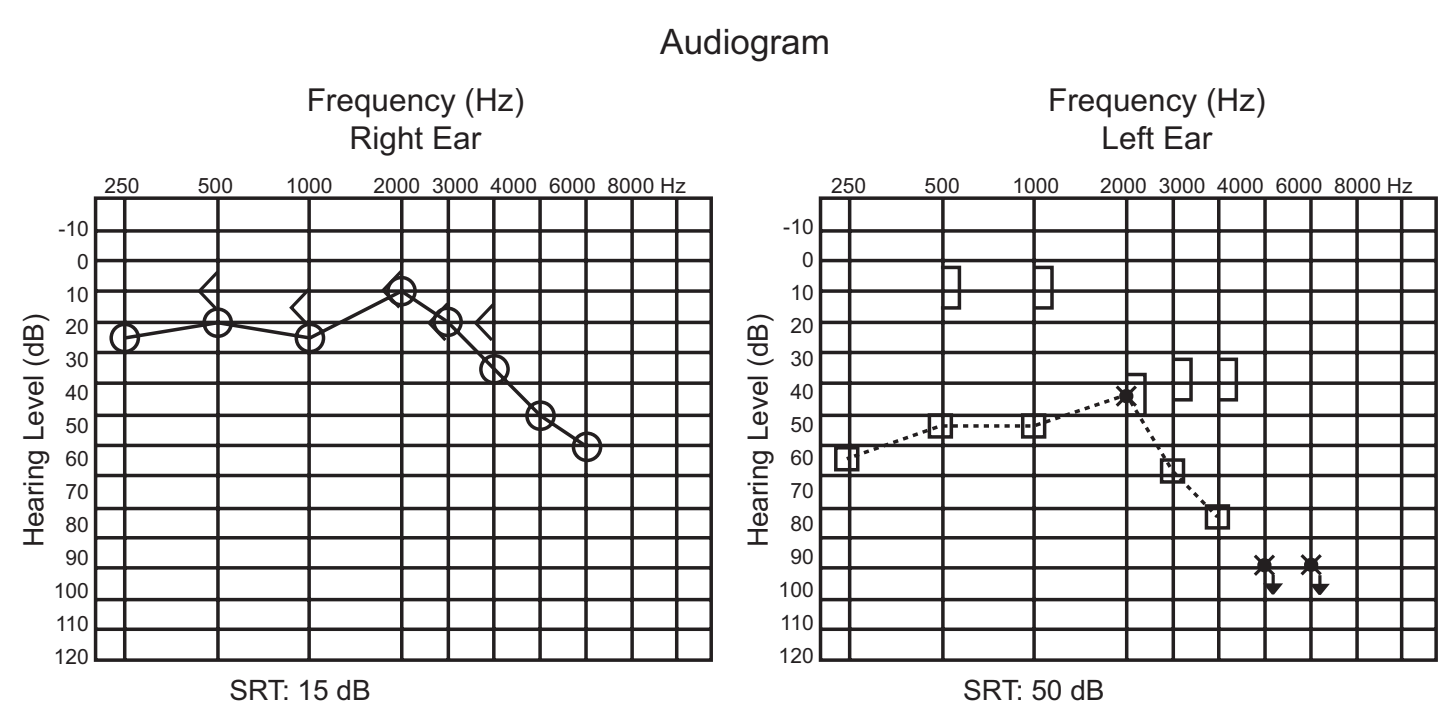

Fig. 4 Audiogram performed after treatment. Abbreviation: SRT, speech reception threshold.

With the onset of steroid (prednisone $60 \mathrm{mg} / \mathrm{d}$ ), the patient's symptoms improved and hearing thresholds recovered significantly after 1 week of treatment ( - Fig. 4). The patient currently uses cyclophosphamide monthly and corticosteroids daily with good clinical and laboratory control.

\section{Discussion}

WG is a rare idiopathic disease, immunologically mediated, which affects the small arteries of the upper and lower respiratory tracts and the kidneys, causing inflammation with necrosis, granuloma formation, and vasculitis in these organs. ${ }^{1-4}$ The average age of diagnosis is usually between 20 and 40 years, and males are affected more than females (1.5:1.0). ${ }^{5}$ Otologic manifestation varies widely, occurring in $\sim 20$ to $60 \%$ of the affected patients, and includes serous otitis media, chronic otitis media, sensorineural hearing loss, vertigo, tinnitus, and facial palsy. ${ }^{4,6}$ Treatment should be started early for a better hearing outcome. ${ }^{7}$ Pulmonary manifestations occur in $45 \%$ of cases at initial presentation and $87 \%$ during the course of the disease. ${ }^{8,9}$ Ocular involvement in WG can be part of the initial presentation of the disease in 8 to $16 \%$ of cases. The majority of studies have reported initial manifestations in ENT, followed by lung, skin, and kidneys. ${ }^{3,10}$ Immunosuppressive drugs are the first-line therapy. ${ }^{1,2,5}$

\section{Final Comments}

In cases of acute ear manifestations with or without hearing loss and with poor response to usual treatments, WG should be included among the possible etiologies. As the prognosis depends on early diagnosis and appropriate treatment, the otolaryngologist plays a decisive role in reducing the morbidity and mortality rate in this disease.

\section{References}

1 Rossini BAA, Bogaz EA, Yonamine FK, Testa JRG, Penido NdeO. Refractory otitis media as the first manifestation of Wegener's granulomatosis. Braz J Otorhinolaryngol 2010;76(4):541

2 Scalcon MRR, Pereira IA, Rachid Filho A, Paiva ES. Manifestação otológica localizada em paciente com granulomatose de Wegener. Rev Bras Reumatol 2008;48(4):253-255

3 Antunes T, Barbas CSV. Granulomatose de Wegener. J Bras Pneumol 2005;31(Suppl 1):S21-S26

4 Pires APBA, Sousa NJA, Sousa RCA, et al. Wegener's granulomatosis presenting with bilateral facial nerve palsy. Acta ORL 2008;26(4): 209-259

5 Rezende CEB, Rodrigues REC, Yoshimura R, Uvo IP, Rapoport PB. Wegener's granulomatosis: a case report. Rev Bras Otorrinolaringol 2003;69:261-265

6 Cahali S, Souza MMA, Silveira MC, Cabali MB, Cahali RB. Wegener's granulomatosis-case report with otological manifestation as first symptom. Braz J Otorhinolaryngol 1997;63(1):72-74

7 Takagi D, Nakamaru Y, Maguchi S, Furuta Y, Fukuda S. Otologic manifestations of Wegener's granulomatosis. Laryngoscope 2002; 112(9):1684-1690

8 Fauci AS, Haynes BF, Katz P, Wolff SM. Wegener's granulomatosis: prospective clinical and therapeutic experience with 85 patients for 21 years. Ann Intern Med 1983;98(1):76-85

9 Cordier JF, Valeyre D, Guillevin L, Loire R, Brechot JM. Pulmonary Wegener's granulomatosis. A clinical and imaging study of 77 cases. Chest 1990;97(4):906-912

10 Correa JC, Azevedo AG, Rubens J, Rocha G. Granulomatose de Wegener: análise de dois casos. J Bras Med 1985;48(6): 34-38 